\title{
LA RELACIÓN DE JESÚS CON LAS MUJERES: ENFOQUE BÍBLICO SOBRE LA VIOLENCIA A LA MUJER
}

\author{
Jesus' Relationship with Women: A Biblical Approach to \\ Violence against Women
}

Stalin Gómez Alarcón

Universidad Femenina Sagrado Corazón, Perú https://orcid.org/0000-0002-3339-3766 warnergomeza@unife.edu.pe

\begin{abstract}
RESUMEN
El presente trabajo es un análisis de tres textos del Evangelio usando el método de las Artes Expresivas aplicado al análisis bíblico. Se analizan los textos desde tres criterios: tacto, cuerpo y espacio. Las artes expresivas son una terapia que pone al centro el arte en un proceso didáctico; crean un espacio seguro para transitar hacia un umbral liminal entre la imaginación y la realidad, poniendo al centro lo que emerge del arte. Dan espacio a los sentidos y con ello al cuerpo de forma significativa a través del movimiento creativo, atendiendo a su narrativa y expresión. En esta presentación llevamos las Artes Expresivas a los textos bíblicos para observar, describir y recoger lo que dicen las imágenes bíblicas, y así, hacer teología para iluminar la realidad concreta de la violencia a la mujer en el Perú.
\end{abstract}

\section{Palabras clave:}

Mujer, violencia, tacto, cuerpo, espacio.

\begin{abstract}
This article analyzes three gospel passages through the Expressive Arts method along with Biblical analysis. The passages are analyzed from three approaches: touch, body, and space. The expressive arts represent a therapy with art as a central element in an educational process. They create a safe environment to move towards a liminal space of imagination and reality, revealing everything that emerges from the arts. Furthermore, the expressive arts release the senses as well as the body significantly through creative movements, focusing on self-expression and body narrative. In this publication, Expressive Arts are applied to biblical passages in order to observe, describe and gather the biblical messages with the aim of conducting theology to enlighten the particular reality of violence against women in Peru.
\end{abstract}

\section{Keywords:}

Woman, violence, touch, body, space 


\section{Contexto social de la violencia a la mujer}

La violencia a la mujer y los feminicidios ${ }^{1}$ son un drama actual en nuestro país. El espacio público es escenario de muerte para ellas. En el 2018, cerramos el año con 131 feminicidios en nuestro país. ${ }^{2}$ Sus cuerpos son abordados con la violencia. Para el 2019 tenemos la cifra de 166 feminicidios ${ }^{3}$, es decir aumentó. Hasta marzo del presente año, tenemos más de 27 mil llamadas por casos de violencia contra la mujer, ${ }^{4}$ el hogar no es un lugar de contención, aclarando que el 90 \% de los casos fueron cometidos por su pareja o expareja o algún familiar de ella. ${ }^{5}$

Abrimos las preguntas: ¿Dios quiere, avala y fomenta el encuentro violento contra las mujeres? ¿qué dice la teología bíblica sobre el cuerpo de la mujer y su libertad? Así mismo, ¿cuál es el trato de Jesús con las mujeres que leemos en los Evangelios? Realmente, ¿jJesús de Nazaret "pasó haciendo el bien a toda criatura" (Hc 10,38 ) o solo a los varones?

\section{Las artes expresivas aplicado a los textos bíblicos}

La fenomenología expresa la relación entre el objeto y la consciencia, sin la representación intermedia llamada idea. La percepción es directa con el objeto para quedarse en el objeto en sí mismo. No hay una interpretación previa, ni la proyección de lo que se quiere entender. El objeto es dado directamente y es recibido con apertura. Las escenas bíblicas las recibimos directamente, el mundo es dado por completo en la vivencia y en sus sentidos (Knill, 2018) de cada personaje femenino de estos textos bíblicos. Usamos esta fenomenología aplicada de las artes expresivas en la lectura bíblica, como método de acercamiento a la Palabra de Dios. De esta forma salimos de preconcepciones e interpretaciones ya diseñadas. Para recibir la belleza y gran novedad del Evangelio. Miramos la escena bíblica como una composición artística que tiene algo novedoso, estético y trascendente.

El descentramiento de las Artes Expresivas es lo nuevo que aparece de forma creativa. Salir del circuito monótono de la vida, liberarse de la forma reiterada de hacer y pensar las cosas. En este caso, las mujeres salen de su sufrimiento y opresión gracias al encuentro con Jesús. El descentramiento es comparado a dar un salto de fe a algo nuevo (Mayorga, 2020) que aparece más allá de nuestros cálculos. Así, nacen nuevas posibilidades para las mismas mujeres de estos textos bíblicos. Ahora, están tejiendo un mundo creativo

1 El feminicidio es el crimen ejercido directamente contra la vida de la mujer, por el solo hecho de su condición de mujer. Es, así mismo, la forma más extrema de violencia porque comporta la muerte de ella.

2 Ver Observatorio de la Igualdad de género para América Latina y el Caribe. https://oig.cepal.org/es/ indicadores/feminicidio

3 Ver Programa Nacional para la prevención y erradicación de la violencia contra las mujeres e integrantes del grupo familiar - Aurora. https://www.mimp.gob.pe/contigo/contenidos/pncontigo-articulos.php?codigo $=39$

4 Ver Plataforma digital única del Gobierno Peruano https://www.gob.pe/institucion/mimp/noticias/152829_ mimp-linea-100-recibio-mas-de-27-mil-llamadas-por-casos-de-violencia-contra-la-mujer

5 Las características de esta violencia a la mujer tienen diferentes aspectos a considerar: la violencia intrafamiliar como el porcentaje mayor; violencia callejera, violencia institucionalizada cuando las estructuras de estado no responden o se niegan a asumir sus responsabilidades; violencia a la mujer por su condición socioeconómica, raza y lengua. También razones socio históricas como el sexismo, patriarcado, androcentrismo y misoginia. Tener presente, además, estereotipos socio culturales de la rezagar a la mujer a espacios determinados. 
en sus cuerpos, relaciones y el espacio. Se dejan sorprender por lo que emerge al estar con Jesús, se entregan a la Poiesis, es decir a la creación de sus vidas, desde sus posibilidades e imaginación. Veremos el descentramiento bello de una nueva vida.

\section{3.- Contexto cultural de la mujer en tiempos de Jesús}

La inferioridad de la mujer en la mentalidad judía está sustentada en la ley judía. Lv 27, 1-7 nos enseña que la mujer vale la mitad o tres partes de un hombre. El divorcio era una potestad garantizada por ley sólo para varones (Dt 24,1-4), las mujeres no tenían más que acatar. Sobre el matrimonio, la ley sí sustentaba al varón tener varias mujeres (Dt 21,15-17), pero a la mujer no.

La naturaleza de su cuerpo femenino era condenada por la religión judía. La mujer estaba manchada una semana al mes por su regulación, era impura naturalmente (Lv 12,2). En el parto de un varón quedaba naturalmente impura los 7 días posteriores, luego de la circuncisión 33 días más. Pero, si nacía una mujer el tiempo de impureza era doble, por el hecho de ser mujer (Lv 12,2-5). Estar impura le significaba a la mujer no participar de los ritos, espacios y cultos.

La mujer era mal vista en la mentalidad judía debido a la interpretación del Génesis (Pagola, 2007). Los textos claves son dos: "ayuda adecuada" (Gn 2,18b) y "dio igualmente a su marido y comió" (Gn 3,6b). De allí se desprende la tutela como forma de control sobre la mujer, estar supeditada al régimen del varón, allí vemos la formulación del decálogo del Sinaí "ni codiciarás la mujer de tu prójimo" (Ex 20,17b) donde la mujer es una propiedad entre otras propiedades del varón. No tenía espacio público libre, dependían del varón, estaban bajo el acuerdo de matrimonio hecho por la familia, sin decisión personal. Suscritas al espacio familiar, sin eso no existían (Pagola, 2007). Pero existen otros textos bíblicos que también expresan la inferioridad de la mujer (Dunn 2001). Así Dt 21,15-17. 24,1 4. Lv 27,1 7.

Jesús transforma este modo de relación entre varones y mujeres proponiendo relaciones igualitarias (Pikaza, 2013). Quita las diferencias por condición sexual que mantenían un patriarcado en base a lo religioso. Esta proclamación del Reino genera un nuevo tacto en las relaciones, un nuevo espacio de relaciones y reubica el cuerpo como lugar de vida y comunión.

\section{4.- La relación entre Jesús y las mujeres}

\section{a. La inclusión de las mujeres en la misión salvífica de Jesús}

Leer el Evangelio en sus cuatro versiones nos revela la cercanía de Jesús con las mujeres. El misterio de la Encarnación, en Lc 1,26ss, nos presenta al ángel Gabriel conversando con la Virgen María sobre su libertad de aceptar ser madre del Salvador. Aquí, María pregunta ¿Cómo será esto? (Lc 1,34), habla y tiene voz personal. Es más, el texto presenta la aceptación de la Virgen María que confirma ejercicio de su libertad (Lc 1,38). Su cuerpo es espacio de vida naciente y contención del Hijo de Dios. No hubo varón mediando la plática entre ella y la voluntad de Dios.

Jesús cuenta con mujeres en la comunidad apostólica porque las valora como personas en sí mismas (Montes, 2006). Ellas le acompañan (Lc 8,2-3) como lo hacen los mismos apóstoles y tienen la responsabilidad de velar por 
los recursos y la administración, dice el texto: "y sucedió a continuación que iba por ciudades y pueblos, proclamando y anunciando la Buena Nueva del Reino de Dios; le acompañaban los Doce, y algunas mujeres que habían sido curadas de espíritus malignos y enfermedades: María, llamada Magdalena, de la que habían salido siete demonios. Juana, mujer de Cusa, un administrador de Herodes, Susana y otras muchas que les servían con sus bienes". Ellas compartían la vida y misión de Jesús. Su presencia femenina rompe con el patrón cultura y de la religión judía y crea una nueva forma de relación con lo femenino dentro de la comunidad apostólica.

\section{b. Tacto profético y sanador de Jesús en contextos de violencia a la mujer.}

\section{El trazo de Jesús en el suelo}

Jesús presencia un acto de violencia física a una mujer, Juan 8, 1-11, texto llamado de la mujer adúltera. El espacio público es el Templo de Jerusalén, lugar del poder religioso, la moral y el culto divino. Pero, en este texto bíblico el templo es espacio de muerte para la mujer. Tomada prisionera es sometida, "la llevan" ante Jesús. La ley ordena matarla por cometer adulterio. Ellos deciden sobre su vida y cuerpo, si vive o muere. No condenan al varón encontrado in fraganti. Sólo ella es responsable del pecado. Es evidente la parcialidad de este juicio que privilegia al varón.

Jesús recibe al tumulto embravecido. El texto bíblico acentúa contrastes: ellos de pie y furiosos, Jesús sentado. Ellos bélicos y en acción grupal, Jesús sólo y tranquilo. Los escribas y fariseos exponen el acto inmoral y la Ley de Moisés, Jesús responde simbólicamente a los legisladores v. 6 "Pero Jesús, inclinándose, se puso a escribir con el dedo en la tierra." El gesto de inclinar y tocar el suelo se asemeja a la adoración divina. ${ }^{6}$ Jesús hace un segundo gesto: el escribir con el dedo en la tierra. Esto tiene relación con lo que dice el profeta Jeremías 17,13:7 "Esperanza de Israel, Yahveh: todos los que te abandonan serán avergonzados, y los que se apartan de ti, en la tierra serán escritos, por haber abandonado el manantial de aguas vivas, Yahveh." El gesto del tacto en la tierra expresó lo que ellos conocían del profeta Jeremías, ${ }^{8}$ además, se abre la reflexión simbólica, gestual y corporal. Es un gesto delicado y desconcertante. El tacto de Jesús denota delicadeza y respeto incluso por el cuerpo acusado y maltratado. La incorporación de Jesús y su Palabra irrumpe el acto violento del grupo: "Aquel de ustedes que esté sin pecado, que le arroje la primera piedra". Con esto, desnuda el velo falso de la pureza social, todos son pecadores. La ley valida la acusación de judíos probos e intachables cuya condición ellos no tenían. Entonces abandonan la escena y se crea un momento de intimidad y el espacio público se transforma en encuentro.

El verso 10 contiene el diálogo de Jesús y la mujer. Le dice, Mujer, el mismo título dado a su madre en la cruz. Enseguida vienen dos preguntas que abren paso a una nueva consciencia social: "¿dónde están? ¿Nadie te ha condenado? Preguntas que la llevan a

6 Ex 34,8. Moisés se postra ante la presencia de Dios que ha bajado. El texto se desarrolla en términos de la Alianza que van a pactar entre Dios y el pueblo de Israel. Lev 26, 1 Nos recuerda que esto sólo era dado para Dios.

7 Cf. https://www.infocatolica.com/blog/espadadedoblefilo.php/1 104201051-algo-escrito-en-la-tierra

8 Sobre este versículo, la teología bíblica, tiene muchas visiones abiertas que posibilita seguir investigando. 
pensar y descubrir su realidad. Ella liberada de la muerte, ahora tiene voz. Entonces, Jesús no la condena e invita a la mujer a realizarse en una nueva vida. Resignifica el cuerpo de la mujer porque es ella quien tiene que construir su nueva historia.

\section{El tacto de la mujer hemorroísa}

Jesús y la hemorroísa Mc 5,25-34 es un texto donde la intimidad femenina es curada en espacio público. ${ }^{9}$ Del v. 25-28: la hemorroísa es tímida y de fe sencilla en el contexto social. Se le describe muchos males: ser mujer la pone en desventaja, desangrando ${ }^{10}$ doce años, (este número simboliza plenitud y perfección que ella perdió) sufrió malos tratamientos médicos, se empobreció y estaba cada vez peor. En principio mantiene su categoría social: "se acerca por detrás" dice el texto. Tiene consciencia de su situación marginal en el espacio público. Pero el autor bíblico da voz a su pensamiento, y expresa su estrategia: tocar a Jesús, su contacto le devolverá la salud. Nuria Calduch (2008) dice que ese encuentro tiene las características de una terapia, es decir, que el trato de Jesús es sanador profundamente, done está el problema y la fuente viva que puede emerger. La terapia es través de lo corpóreo en un trato limpio y claro de sanación de su corazón. La energía cálida de Jesús ofrece vida integral para sus interlocutores. El cuerpo de Jesús es sanador y contenedor.

La hemorroisa se sabe impura, pues la sangre derramada era una mancha negativa a los ojos de Dios. Esto explica el temor y miedo de ser apartada y encadenada por estar en medio de la gente. El gesto de tocar, querer solucionar y probar, es una transgresión de las costumbres y la cultura. Ella como pecadora por la sangre que emana debe estar lejos de la gente, pero se revela y actúa desde el tacto. No es violencia, no necesita más que recurrir a la mano y el tacto.

Dice el texto bíblico v. 29: "...y sintió en su cuerpo que quedaba sana del mal". Jesús da salud pública a la mujer que se desangraba. Se pone a la luz de todos cuando Jesús la visibiliza: ¿Quién me tocó? Revela su identidad en el espacio público, con su cuerpo sano. Está tocando a Dios hecho hombre de forma diferente en medio de una multitud, le dicen: "Estás viendo que la gente te oprime y preguntas: "¿Quién me ha tocado?". V31b. Pero el tacto de ella es diferente, tiene acceso a Jesús desde su feminidad, intimidad y riesgo.

\section{Derroche sensorial de amor}

Sobre la mujer pecadora, Lc 7,36-50 nos narra que ingresa a una comida de Jesús con los fariseos. Ella es mala en sí misma a los ojos de los "santos", su presencia comunica el mal. Su cuerpo es rechazo en el espacio tomado por personas aparentemente justas. La violencia de sus pensamientos lo revelan: pecadora. No tiene rango social, está en la última fila ${ }^{11}$.

Lucas presenta a Jesús marcadamente diferente. Él acepta la irrupción de ella, se deja pasivo y receptivo a las acciones

9 Nuria Calduch-Beneges. La mujer sería el único caso en los Evangelios de una mujer que tiene una hemorragia ginecológica. Pg. 16.

10 En la mentalidad judía la sangre es espíritu de la persona misma, similar a identidad de su persona en la mentalidad occidental.

11 Nuria Calduch. "La mujer tiene ya estigmas sociales: es mujer, lo que la margina de muchas formas. Pero, ella está en desventaja social en muchos casos. Pues, la importancia de alguien está a en su puesto social y situación personal. "la mujer del perfume no es "farisea", no es "rabina", no es letrada. Es solamente pecadora de renombre, y, para colmo mujer." Pg. 65. 
abundantes de ella. Leemos el texto, v.38: "y poniéndose detrás, a los pies de él, comenzó a llorar, y con sus lágrimas le mojaba los pies y con los cabellos de su cabeza se los secaba; besaba sus pies y los ungía con el perfume". Son verbos activos que denotan total desborde de amor. Permite la expresión física, sensible de su tacto. Todo el lenguaje físico y sensual de la mujer es amor, dice Calduch (2008) expresa la fuerza del amor que expresa la mujer, la manifestación de su carga emocional dirigido a Jesús.

El banquete tenía mala fama por los recaudadores de impuestos, ya que invitaban a prostitutas. El escándalo está en la misericordia de Jesús con los pecadores del medio social y público, es decir, son los pecadores conocidos por todos. Por eso, la irrupción de la mujer trae a la mente de los participantes este contexto de social y los prejuicios. Pero, Jesús lo permite y rompe el espacio de la pureza de los fariseos. (Pagola 2007).

Jesús no juzga como malo el comportamiento de la mujer. No es condenada por su expresión libre de amor hacia él. Su feminidad no es juzgada ni controlada. Ella solo se expresa en un acto de fe y amor. Es más, Jesús la defiende narrando la parábola sobre el perdón. Jesús tiene claro que está arrepentida y no confunde nada de ella. Se convierte en espacio seguro, donde hay un vínculo sano y donde tiene sentido profundo la expresión gestual. Entonces, el diálogo del cuerpo es ya una terapia que reconstruye esa violencia contra la mujer. El lenguaje del cuerpo está dando un mensaje de Buena Nueva, Jesús deja a la mujer en su rito de amor, en su gesto y lenguaje femenino. Se está reparando la historia de ella y su relación con el medio social y público. Es un derroche sensorial de amor reparador.

\section{Propuesta para una relación con las mujeres desde Jesucristo}

El Evangelio invita a mirar el mundo desde una perspectiva integral para crear sociedades que erradiquen la violencia sin ninguna justificación social, cultural y mucho menos religiosa. El Dios que revela Jesús no es violento contra las mujeres, rechaza la muerte en especial de las más frágiles en la sociedad. La teología nos hace ver otras alternativas de convivencia social: la reubicación del cuerpo femenino en el espacio social que demanda de cuidado, seguridad e inclusión de su feminidad. La propuesta de Jesús genera algo que afecta al sistema patriarcal (Pagola, 2007). Jesús realizó una acción novedosa pública, directa con todo el carisma profético, frente a los agentes de la muerte. Porque la inclusión de la mujer en la sociedad también se dio en la comunidad apostólica de igualdad entre varones y mujeres. De este modo, el reino de Dios presentado por Jesús es una propuesta integradora, holística e inclusiva de las mujeres. La inclusión de mujeres en el discipulado de Jesús, junto con los apóstoles, significó un escándalo y rechazo (Montes, 2006) por alejarse de la costumbre de su tiempo, donde ninguna mujer podía ser discípula, estaban negadas a aprender.

Las Artes Expresivas nos permiten ver la belleza del actuar de Jesús que renueva las facultades de las mujeres. Lejos de la violencia y el maltrato nos centra en un marco terapéutico de la misión de Jesús. Ahora, ellas mismas son las protagonistas de sus vidas, con la novedad de construirse en sus cuerpos como lugar de vida y espacios de seguridad e integración. Alejándose de las cifras de muerte y dolor que se infringía en un contexto negativo para ellas. El tacto de Jesús es revitalizador y catapulta la 
novedad y frescura de un nuevo empezar rechazando todo tipo de violencia a la mujer. Es un acto transformador de su realidad individual y de su contexto de vida, el fruto primero es la resiliencia en todo lo vivido (Llanos, 2020).

El Papa Francisco, en el documento Fratelli Tutti (45) nos recuerda ese dolor de la violencia y abuso en las mujeres, como una herida que pertenece a toda la humanidad. Es un problema del ser humano en su integridad, esa violencia genera más violencias y más víctimas en las relaciones humanas. Tenemos que romper esa cadena de violencia de forma unida, en comunidad con todas las instancias e instituciones. Así, la misma Iglesia Católica muestra su disponibilidad.

Valoramos la sensibilidad de la Iglesia Católica en la actualidad que aprobó los ministerios laicales del Lectorado y Acolitado para las mujeres, según está oficializado por el Motu Proprio de Modificación del canon $230 \oint 1$. del Derecho Canónico, publicado el 11 de enero del presente 2021. Da paso oficial al rol de la mujer en el servicio laico del altar. Hemos de recordar que estos ministerios laicales estaban reservados sólo para varones y en la práctica se celebraba como preparación a los candidatos al sacerdocio ministerial. La importancia de esta decisión está en la reflexión y disposición eclesial de actualizarse y validar el cuerpo de la mujer en el espacio sagrado de la celebración de los sacramentos, sin ninguna discriminación. Esta decisión es una respuesta a las necesidades de los tiempos presentes, como lo expresa el mismo documento eclesial. La mujer tiene la misma dignidad del varón, y el reconocimiento de su sacerdocio real propio del bautismo sobre el que recae dichos ministerios.
El Papa Francisco, también, expresa la fuerza de la mujer en la figura de María Santísima, mujer capaz de sostener, acompañar y cobijar (ChV 45). Verbos que se expresan con el movimiento del cuerpo y gestos que significan protección de la vida. Esta aptitud femenina les hace custodias de la esperanza y líderes para crear espacios públicos seguros y cuidados, para ellas y todas las personas. Las mujeres tienen todas las capacidades para seguir construyendo la sociedad de la convivencia y la igualdad. Es un "Sí" como María, con creatividad y entereza, en unidad entre varones y mujeres construyendo una nueva sociedad con tacto, cuerpo y espacio armónico.

\section{REFERENCIAS BIBLIOGRÁFICAS}

Calduch-Beneges, N. (2008). "El perfume del Evangelio. Jesús se encuentra con las mujeres". Verbo Divino.

Comisión Nacional de los Derechos Humanos (CNHDH) (2018). Violencia Institucional contra las mujeres. https:// www.cndh.org.mx/sites/default/ files/documentos/2019-04/41 CARTILLA ViolenciaContra Mujeres.pdf

Comisión Económica para América Latina y el Caribe (CEPAL). (2020). Observatorio de la Igualdad de género para América Latina y el Caribe. https://oig.cepal.org/es/ indicadores/feminicidio Pagola José A. (2007). Jesús. Aproximación histórica. PPC.

Peiró, C. (2016). Jesús, "el hombre que amaba las mujeres". https://www. infobae.com/2016/03/27/1799914 jesus-el-hombre-que-amaba-lasmujeres/ 
Francisco, Santo Padre. (2020). Carta Encíclica Fratelli Tutti. Sobre la Fraternidad y la amistad social. Vaticano.

Francisco, Santo Padre. (2019). Exhortación Apostólica Postsinodal Christus Vivit. A los jóvenes de todo el mundo. Vaticano.

Knill, Paolo. (2018). Principios y práctica de la Terapia de Artes Expresivas. Hacia una estética terapéutica. Terapia de Artes Expresivas.

M, Bruno (2011). (20 de abril de 2011 ). Algo escrito en la tierra. Blog de Bruno M. https://www.infocatolica. com/blog/espadadedoblefilo. php/1 104201051 -algo-escrito-enla-tierra

Ministerio de la Mujer y Poblaciones Vulnerables (MMPV). (2020). https:// www.gob.pe/institucion/mimp/ noticias/152829-mimp-linea-100recibio-mas-de-27-mil-llamadaspor-casos-de-violencia-contra-lamujer

Ministerio de la Mujer y Poblaciones Vulnerables (MMPV). (2020). Programa Nacional para la prevención y erradicación de la violencia contra las mujeres e integrantes del grupo familiar -
Aurora. https://www.mimp.gob.pe/ contigo/contenidos/pncontigoarticulos.php? codigo $=39$

Pikaza, Xavier. (2013). Historia de Jesús. Editorial Verbo Divino.

Papa Francisco. (2021). arta apostólica "Spiritus Domini" en forma de "Motu Proprio "sobre la modificación del canon 230 § 1 del Código de Derecho Canónico acerca del acceso de las mujeres al ministerio instituido del lectorado y acolitado. https://press.vatican.va/ content/salastampa/es/bollettino/ pubblico/2021/01/11/carta.html.

Montes Peral, Luis Ángel. (2006). Tras las huellas de Jesús. Seguimiento $y$ discipulado en Jesús. Los evangelios y el evangelio de dichos Q. Estudios y Ensayos. Biblioteca de Autores Cristianos. Teología.

Llanos Zuloaga, Martha. (2020). Arte, creatividad y resiliencia. Recursos frente a la pandemia. Revista Avances en Psicología. UNIFÉ. ISSN 2708-5007. https://revistas.unife.edu.pe/index. php/avancesenpsicologia/article/ view/2248/2325

Ubieta López J.A. (1998). Biblia de Jerusalén. Desclée de Brouwer.

Fecha de recepción: 12/11/2020

Fecha de aceptación: 27/1 1/2020 